\title{
Assessment of Levels of Knowledge towards Hormonal Related Breast Cancer Risk Factors in Qurayyat, Northern Saudi Arabia
}

\author{
Abdelbaset Mohamed Elasbali' ${ }^{1}$ Elyasa Mustafa Elfakia Mohammed1', Ziad Alonzi², \\ Rania Abdeen Hussain Abdalla3 ${ }^{3}$, Azizah Mazi Aldaham¹, Diem Fayez Aljubab1, \\ Naif Muflih Alsharari'1, Hussain Gadelkarim Ahmed ${ }^{4,5}$ \\ ${ }^{1}$ Department of Clinical Laboratory Sciences, College of Applied Medical Sciences, Jouf University, Qurayyat, KSA \\ ${ }^{2}$ Department of Clinical Laboratory Sciences, College of Applied Medical Science, Jouf University, Sakaka, KSA \\ ${ }^{3}$ Department of Obstetrics and Gynecology, College of Medicine, University of Hail, Hail, KSA \\ ${ }^{4}$ College of Medicine, University of Hail, Hail, KSA \\ ${ }^{5}$ Department of Histopathology and Cytology, FMLS, University of Khartoum, Khartoum, Sudan \\ Email: hussaingad@gmail.com
}

How to cite this paper: Elasbali, A.M., Mohammed, E.M.E., Alonzi, Z., Abdalla, R.A.H., Aldaham, A.M., Aljubab, D.F., Alsharari, N.M. and Ahmed, H.G. (2019) Assessment of Levels of Knowledge towards Hormonal Related Breast Cancer Risk Factors in Qurayyat, Northern Saudi Arabia. Open Journal of Obstetrics and Gynecology, 9, 371-381. https://doi.org/10.4236/ojog.2019.93038

Received: February 15, 2019

Accepted: March 9, 2019

Published: March 12, 2019

Copyright () 2019 by author(s) and Scientific Research Publishing Inc. This work is licensed under the Creative Commons Attribution International License (CC BY 4.0).

http://creativecommons.org/licenses/by/4.0/

(c) (i) Open Access

\begin{abstract}
Background: Continued exposure to sex hormones such as estrogen is a critical risk for subsequent breast cancer. Thus the present study aimed to assess the levels of knowledge towards hormonal related breast cancer risk factors in Qurayyat, Northern Saudi Arabia. Methodology: This descriptive study included 737 Saudi volunteers living in the city of Qurayyat, Northern Saudi Arabia. For females, only those agreeing to participate in the breast self-examination workshop were included, and non-respondents were included in the questionnaire. Results: For the question apropos "Inheritance as a risk factor for BC," 405/607 (66.7\%) females signposted certainly "Yes," as well as, 70/130 (54\%) males signposted certainly "Yes." The odds ratio (OR) and 95\% confidence interval (95\% CI) were not statistically significant, but the level of knowledge was relatively higher among females OR (95\% CI) $=1.4321$ ( 0.9597 to 2.1370$), \mathrm{P}=0.0786$. "Are early puberty and late menopause risk factors for breast cancer?" No statistical significant differences were eminent between males and females, OR $(95 \% \mathrm{CI})=0.8878$ (0.5932 to $1.3287), \mathrm{P}=0.5629$. Conclusion: Saudi women are enthusiastically willing to raise their knowledge and awareness of breast cancer prevention and control. Although women have greater knowledge about breast cancer risk factors compared to men, still some gaps need to be filled.
\end{abstract}

\section{Keywords}

Breast Cancer, Hormones, Risk Factors, Estrogen, Saudi Arabia, Alquriat 


\section{Introduction}

Breast cancer is the commonest, complex, and heterogeneous neoplasm and the most common cause of cancer death among females worldwide [1] [2]. Although the information on the epidemiology of breast cancer is frequently changing, it is increasingly dominant females' cancer, accounting for $25.1 \%$ of all cancers, according to GLOBOCAN [3]. The prevalence of breast cancer is higher in the developed world compared to developing countries with the most significant mortality in the later. Education of women, early detection, and increasing awareness are the primary prevention and control measures, particularly for the less developed countries [4]. Such efforts have reduced the age-standardized mortality, as well as, improved the relative survival for many countries. The recent positive changes in the epidemiology of breast cancer are strongly linked to early detection programs, such as mammography screening [5].

In Saudi Arabia, breast cancer is the commonest females' cancer with a prevalence of $21.8 \%$ [6], and it represents the $9^{\text {th }}$ leading cause of death in the country [6] [7] [8]. In recent years there was a significant increase in the number of new patients with breast cancer, particularly among younger females population compared to new patients in Western nations [9]. Sex hormones extra exposure, exactly estrogen is incriminated in the etiology of breast cancer. The majority of breast cancer risk factors may interact through hormone-related pathways, particularly estrogen, which is firmly connected to the elevated risk of breast cancer in postmenopausal women [10]. Consequently, the present study aimed to assess the levels of knowledge towards hormonal related breast cancer risk factors in Qurayyat, Northern Saudi Arabia.

\section{Materials and Methods}

This descriptive study included 757 Saudi volunteers living in the city of Qurayyat, Northern Saudi Arabia, during the period from October 2018 to February 2019. Sample size was calculated using software calculator.net: available at: https://www.calculator.net/sample-size-calculator.html. Participants were targeted in different public settings in the city. Participants were randomly selected by simple random method regardless of age, gender, education level or occupation. For females, only those agreeing to participate in the breast self-examination workshop were included, and non-respondents were included in the questionnaire. A total of 130 men were enrolled as an internal control. Males' participants were added to serve as an internal control for the obtained information regarding breast cancer previous knowledge. A purposeful inquiry was designed and used for getting the necessary data. Besides, age, sex, and education level, the questionnaire included questions: Inheritance as a risk factor for $\mathrm{BC}$; early puberty and late menopause are risk factors for $\mathrm{BC}$; delayed childbirth is a risk for $\mathrm{BC}$; natural breastfeeding is a risk for $\mathrm{BC}$; hormonal usage is a risk for $\mathrm{BC}$. 


\subsection{Data Analysis}

Statistical Package for Social Sciences (version 16) was used for analysis and to perform a Pearson Chi-square test for statistical significance (P-value). The 95\% confidence level and confidence intervals were used. A p value less than 0.05 was considered statistically significant.

\subsection{Ethical Consent}

Each participant was asked to sign a written ethical consent during the questionnaire's interview. The informed ethical consent form was designed and approved by the ethical committee of the Applied Medical Science (Qurayyat. Jouf University, Saudi Arabia) Research Board.

\section{Results}

Out of the 757 approached women, 473/757 (62.5\%) responded to partake in breast self-examination training. The mean age of the contributors was $35.7 \pm$ 10.5 years with a minimum of 17 and a maximum of 72 years old. A total of 130 men were enrolled as an internal control. The question relevant "Inheritance as a risk factor for BC," 405/607 (66.7\%) females signposted certainly "Yes," as well as, 70/130 (54\%) males signposted certainly "Yes." The odds ratio (OR) and 95\% confidence interval $(95 \% \mathrm{CI})$ was not statistically significant, but the level of knowledge was relatively higher among females OR $(95 \% \mathrm{CI})=1.4321$ (0.9597 to 2.1370), $\mathrm{P}=0.0786$, as indicated in Table 1, Figure 1.

The question "Whether early puberty and late menopause are risk factors for BC," 190/623 (30.5\%), 77/623 (12.4\%), and 356/623 (57\%) of the females replied "Yes" increase the risk of $\mathrm{BC}$," "Yes decrease the risk of $\mathrm{BC}$," and "No do nothing," respectively. About 43/130 (33\%), 44/130 (34\%), and 43/130 (33\%) of the males replied "Yes increase the risk of BC," "Yes decrease the risk of $\mathrm{BC}$," and "No do nothing," in that order. No statistical significant differences were eminent between males and females, OR $(95 \% \mathrm{CI})=0.8878$ (0.5932 to 1.3287$), \mathrm{P}=$ 0.5629 (see Table 1, Figure 1).

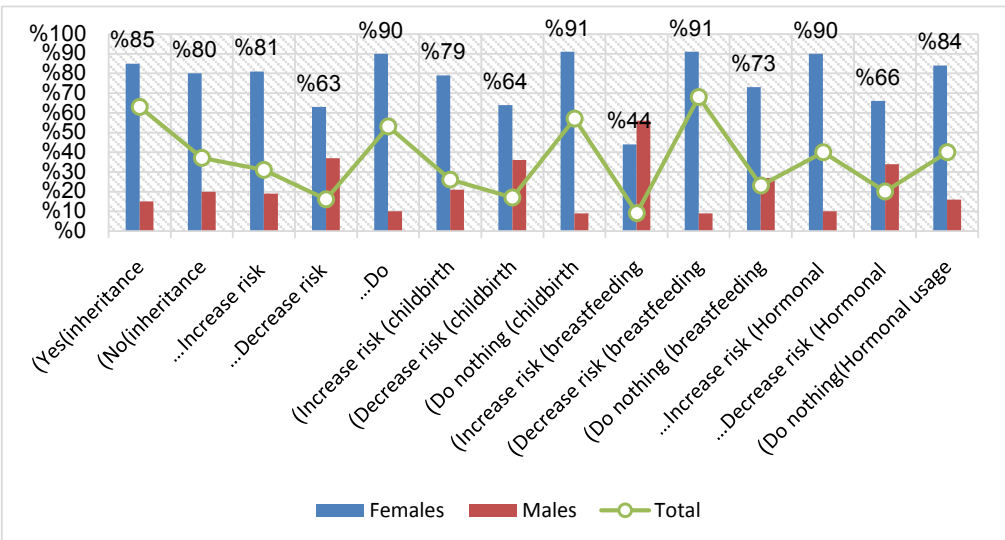

Figure 1. Gender and hormonal-related breast cancer risk factors. 
Table 1. Distribution of study subjects by gender and hormonal-related breast cancer risk factors.

\begin{tabular}{|c|c|c|c|}
\hline Variable & Females & Males & Total \\
\hline \multicolumn{4}{|l|}{ Role of inheritance in $B C$} \\
\hline Yes & 405 & 70 & 475 \\
\hline No & 202 & 50 & 252 \\
\hline Total & 607 & 130 & 727 \\
\hline \multicolumn{4}{|c|}{ Early puberty and late menopause are risk factors for $B C$} \\
\hline Increase the risk of $\mathrm{BC}$ & 190 & 43 & 234 \\
\hline Decrease the risk of $\mathrm{BC}$ & 77 & 44 & 122 \\
\hline Do nothing & 356 & 43 & 397 \\
\hline Total & 623 & 130 & 753 \\
\hline \multicolumn{4}{|c|}{ Delayed childbirth is a risk } \\
\hline Increase the risk of $\mathrm{BC}$ & 148 & 40 & 188 \\
\hline Decrease the risk of $\mathrm{BC}$ & 90 & 50 & 140 \\
\hline Do nothing & 386 & 40 & 426 \\
\hline Total & 624 & 130 & 754 \\
\hline \multicolumn{4}{|l|}{ Natural breastfeeding } \\
\hline Increase the risk of $\mathrm{BC}$ & 31 & 40 & 71 \\
\hline Decrease the risk of $\mathrm{BC}$ & 469 & 44 & 513 \\
\hline Do nothing & 122 & 46 & 168 \\
\hline Total & 618 & 130 & 752 \\
\hline \multicolumn{4}{|l|}{ Hormonal usage } \\
\hline Increase the risk of $\mathrm{BC}$ & 268 & 30 & 298 \\
\hline Decrease the risk of $\mathrm{BC}$ & 99 & 52 & 151 \\
\hline Do nothing & 250 & 48 & 298 \\
\hline Total & 617 & 130 & 747 \\
\hline
\end{tabular}

The question "Whether delayed childbirth is a risk for BC," 148/624 (24\%), 90/624 (14.4\%), and 386/624 (62\%) of the females replied "Yes increase the risk of $\mathrm{BC}$," "Yes decrease the risk of $\mathrm{BC}$," and "No do nothing," correspondingly. Around 40/130 (31\%), 50/130 (38\%), and 40/130 (31\%) of the males replied "Yes increase the risk of $\mathrm{BC}$," "Yes decrease the risk of $\mathrm{BC}$," and "No do nothing," in that order. No statistical significant differences were eminent between males and females, OR $(95 \% \mathrm{CI})=0.6996$ (0.4617 to 1.0601$), \mathrm{P}=0.0920$ (see Table 1, Figure 1).

The question "Whether natural breastfeeding is a risk for BC," 31/618 (5\%), $469 / 618$ (75\%), and 122/618 (20\%) of the females replied "Yes increase the risk of $\mathrm{BC}$," "Yes decrease the risk of $\mathrm{BC}$," and "No do nothing," correspondingly. Around 40/130 (31\%), 44/130 (34\%), and 46/130 (35\%) of the males replied "Yes 
increase the risk of BC," "Yes decrease the risk of BC," and "No do nothing," in that order. The knowledge of the females on the subject of "natural breastfeeding," as a factor lowering the risk of BC was found statistically significant, OR $(95 \% \mathrm{CI})=5.9914$ (3.9899 to 8.9968), $\mathrm{P}<0.0001$ (see Table 1, Figure 1).

The question "Whether hormonal usage is a risk for BC," 268/617 (43.4\%), 99/617 (16\%), and 250/617 (40.5\%) of the females replied "Yes increases the risk of $\mathrm{BC}$," "Yes decrease the risk of $\mathrm{BC}$," and "No do nothing," correspondingly. Around 30/130 (23\%), 52/130 (40\%), and 48/130 (37\%) of the males replied "Yes increases the risk of $\mathrm{BC}$," "Yes decrease the risk of $\mathrm{BC}$," and "No do nothing," in that order. The knowledge of the females on the subject of "Hormonal usage," as a factor hovering the risk of BC was found statistically significant, OR (95\% CI) $=2.5597$ (1.6519 to 3.9664), $\mathrm{P}<0.0001$ (see Table 1, Figure 1).

Knowledge regarding "Inheritance as a risk for $B C$," predominantly merit by age group 26 - 35 years 93/195 (48\%) followed by 36 - 45 years $45 / 195$ (23\%) and 46 - 55 years $24 / 195$ (12.3\%).

Knowledge regarding "Early puberty and late menopause are risk factors for $B C$," suggestion "increased the risk of $\mathrm{BC}$ " was predominantly specified by age group 26 - 35 years $91 / 190$ (48\%) followed by 36 - 45 years 55/190 (29\%) and 46 - 55 years $21 / 190(11 \%)$.

Knowledge regarding "Delayed childbirth is a risk," submission "increased the risk of BC" was predominantly stated by age group 26 - 35 years 71/148 (48\%) followed by 36 - 45 years 50/148 (34\%) and 46 - 55 years 10/148 (7\%).

Knowledge regarding "Natural breastfeeding," submission "increased the risk of BC" was predominantly stated by age group 36 - 45 years $10 / 31$ (32\%) followed by 26 - 35 years $8 / 31$ (26\%) and $\leq 25$ years $5 / 31$ (16\%).

Knowledge regarding "Hormonal usage, as BC risk factor," idea "increased the risk of BC" was predominantly specified by age group 26 - 35 years 125/269 (46.5\%) followed by 36 - 45 years $71 / 269$ (26.4\%) and 46 - 55 years 35/269 (13\%), as shown in Table 2, Figure 2.

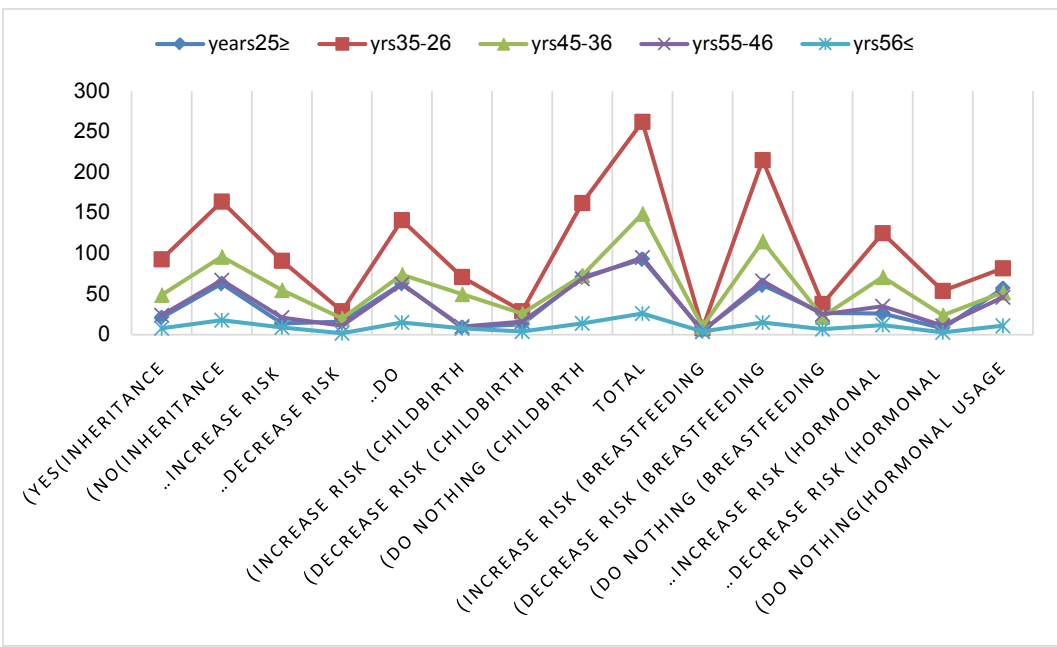

Figure 2. Age and hormonal-related breast cancer risk factors. 
Table 2. Distribution of study subjects by age and hormonal-related breast cancer risk factors.

\begin{tabular}{lcccccc}
\hline \multicolumn{1}{c}{ Variable } & $\mathbf{2 5}$ years & $\mathbf{2 6 - 3 5}$ & $\mathbf{3 6 - 4 5}$ & $\mathbf{4 6 - 5 5}$ & $\mathbf{2 5 6}$ & Total \\
\hline Inheritance as a risk for $B C$ & & & & & & \\
Yes & 21 & 93 & 49 & 24 & 8 & 195 \\
No & 63 & 164 & 96 & 67 & 18 & 408 \\
Total & 84 & 257 & 145 & 91 & 26 & 603
\end{tabular}

Early puberty and late menopause are risk factors for $B C$

$\begin{array}{lcccccc}\text { Increase the risk of BC } & 14 & 91 & 55 & 21 & 9 & 190 \\ \text { Decrease the risk of BC } & 16 & 29 & 20 & 11 & 2 & 78 \\ \text { Do nothing } & 63 & 141 & 74 & 62 & 15 & 355 \\ \text { Total } & 93 & 261 & 149 & 94 & 26 & 623 \\ \text { Delayed childbirth is a risk } & & & & & & \\ \text { Increase the risk of BC } & 9 & 71 & 50 & 10 & 8 & 148 \\ \text { Decrease the risk of BC } & 13 & 29 & 26 & 16 & 4 & 88 \\ \text { Do nothing } & 71 & 162 & 73 & 69 & 14 & 389 \\ \text { Total } & 93 & 262 & 149 & 95 & 26 & 625 \\ \text { Natural breastfeeding } & & & & & & 472 \\ \text { Increase the risk of BC } & 5 & 8 & 10 & 4 & 4 & 31 \\ \text { Decrease the risk of BC } & 61 & 215 & 115 & 66 & 15 & 472 \\ \text { Do nothing } & 27 & 38 & 22 & 25 & 7 & 119 \\ \text { Total } & 93 & 261 & 147 & 95 & 95 & 622\end{array}$

Hormonal usage

\begin{tabular}{lcccccc} 
Increase the risk of BC & 26 & 125 & 71 & 35 & 12 & 269 \\
Decrease the risk of BC & 8 & 54 & 24 & 11 & 3 & 100 \\
Do nothing & 57 & 82 & 52 & 46 & 11 & 128 \\
Total & 91 & 261 & 147 & 92 & 26 & 617 \\
\hline
\end{tabular}

As regards to the inquiry "whether inheritance as a risk for $B C$," around 252/727 (34.7\%) participants replied "Yes," including 130/252 (51.6\%), 62/252 (24.6\%) and 38/252 (15\%) subjects with the university, secondary and basic levels of educations, respectively.

As regards to the enquiry "Early puberty and late menopause are risk factors for BC," around 233/727 (32\%) participants replied "Yes," including 140/233 (60\%), 39/233 (16.7\%) and 34/233 (14.6\%) subjects with university, Basic and secondary levels of educations, correspondingly.

As regards to the inquiry "whether Delayed childbirth is a risk," around 189/727 (26\%) participants replied "Yes," including 110/189 (58\%), 33/189 
(17.5\%) and $32 / 189(17 \%)$ subjects with the university, basic and secondary levels of educations, respectively.

As regards to the inquiry "whether natural breastfeeding," around 71/727 (9.8\%) participants replied "Yes," including 33/71 (46.5\%), 20/71 (28\%) and $11 / 71(15.5 \%)$ subjects with the university, basic and secondary levels of educations, respectively.

As regards to the enquiry "whether natural breastfeeding," around 300/727 (41.3\%) participants replied "Yes," including 179/300 (60\%), 59/300 (20\%) and $41 / 300(14 \%)$ subjects with university, basic and secondary levels of educations, respectively, as indicated in Table 3, Figure 3.

\section{Discussion}

Breast is a highly responsive organ to the levels of hormones, particularly estrogen (ER). Prolonged and increased exposure to ER is known to be risk factors for breast cancer.

The present study attempted to highlight the pertained knowledge and awareness levels of Saudi women toward exposure to variable ER-related conditions. At present, there is amassing regarding the role of endogenous ER as a risk for the development of breast cancer. ERs and ERs-related metabolites were extensively investigated in both premenopausal and postmenopausal women, and the results showed substantial hormonal deviations [10].

In the present study, $66.7 \%$ of the participated women stated that the inheritance of breast cancer genes is a critical risk factor for breast cancer. Family history is an essential factor for the determining of the overall risk of breast cancer. A family history score depends on noticed breast cancers in a family, and the following prediction may offer a better view of breast cancer incidence than classical parameters based solely on affected relatives [11]. Individuals carrying a mutation in BRCA1/BRAC2 genes have an elevated lifetime risk of breast cancer $(60 \%-85 \%)$ compared to $12.5 \%$ of women with intact BECA genes [12].

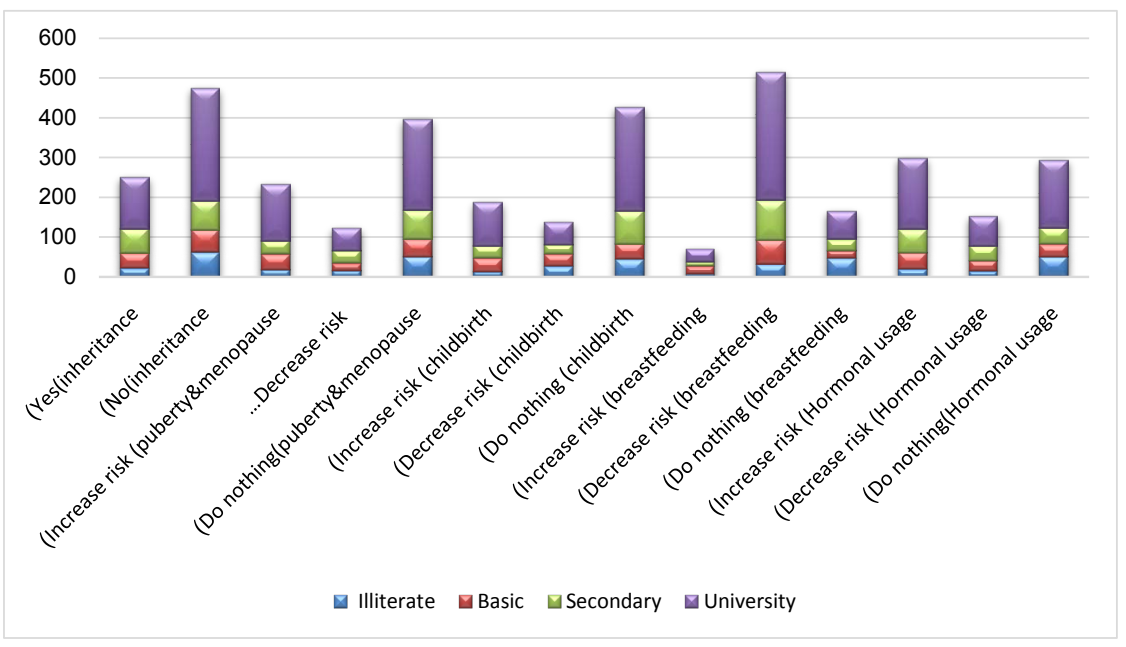

Figure 3. Education and hormonal-related breast cancer risk factors. 
Table 3. Distribution of study subjects by education and hormonal-related breast cancer risk factors.

\begin{tabular}{|c|c|c|c|c|c|}
\hline Variable & Illiterate & Basic & Secondary & University & Total \\
\hline \multicolumn{6}{|l|}{ Inheritance in $B C$} \\
\hline Yes & 22 & 38 & 62 & 130 & 252 \\
\hline No & 63 & 56 & 73 & 283 & 475 \\
\hline Total & 85 & 98 & 135 & 411 & 727 \\
\hline \multicolumn{6}{|c|}{ Early puberty and late menopause are risk factors for $B C$} \\
\hline Increase the risk of $\mathrm{BC}$ & 19 & 39 & 34 & 140 & 233 \\
\hline Decrease the risk of $\mathrm{BC}$ & 17 & 18 & 31 & 57 & 123 \\
\hline Do nothing & 51 & 44 & 74 & 228 & 397 \\
\hline Total & 87 & 101 & 139 & 425 & 753 \\
\hline \multicolumn{6}{|c|}{ Delayed childbirth is a risk } \\
\hline Increase the risk of $\mathrm{BC}$ & 14 & 33 & 32 & 110 & 189 \\
\hline Decrease the risk of $\mathrm{BC}$ & 27 & 31 & 24 & 56 & 138 \\
\hline Do nothing & 46 & 38 & 83 & 260 & 428 \\
\hline Total & 87 & 102 & 139 & 424 & 754 \\
\hline \multicolumn{6}{|l|}{ Natural breastfeeding } \\
\hline Increase the risk of $\mathrm{BC}$ & 7 & 20 & 11 & 33 & 71 \\
\hline Decrease the risk of $\mathrm{BC}$ & 33 & 61 & 100 & 320 & 516 \\
\hline Do nothing & 47 & 20 & 28 & 71 & 166 \\
\hline Total & 87 & 101 & 139 & 423 & 752 \\
\hline \multicolumn{6}{|l|}{ Hormone usage } \\
\hline Increase the risk of $\mathrm{BC}$ & 20 & 41 & 59 & 179 & 300 \\
\hline Decrease the risk of $\mathrm{BC}$ & 15 & 27 & 37 & 73 & 153 \\
\hline Do nothing & 51 & 32 & 42 & 169 & 294 \\
\hline Total & 86 & 100 & 138 & 421 & 747 \\
\hline
\end{tabular}

The question "Whether early puberty and late menopause are risk factors for BC," about $30.5 \%$ of the females replied "Yes" increase the risk of BC. This relatively lower percentage is indicating poor knowledge in this segment. It was well established that early puberty, late menopause, and later age at first pregnancy are risk factors for breast cancer [13].

The question "Whether delayed childbirth is a risk for BC," only $14.4 \%$ of the females replied, "Yes decrease the risk of BC." Modifications in family designs could, however, clarify the elevated risk since giving birth to a first child late in life and bearing few children both upsurge the risk of breast cancer [14].

The question "Whether natural breastfeeding is a risk for BC," $75 \%$ of the females replied, "Yes decreases the risk of BC." The combination of extended breastfeeding and extra childbirth lowers breast cancer risk powerfully, and that 
women who practiced either two or more childbirths and breastfed for $\geq 13$ months can decrease their breast cancer risk by approximately $50 \%$ [15].

The question "Whether Hormonal usage is a risk for BC," $43.4 \%$ of the females replied, "Yes increases the risk of BC." Endogenous estradiol and estrone are concomitant causally to amplified risks of breast cancer [16]. The proof is growing proposing that totaling progestogens to estrogens can raise the risk of breast cancer. Nonetheless, there is an indication that the natural progesterone and dydrogesterone, perhaps furthermore the transdermal use of synthetic progestogens, may have reduced risks, but this needs to be verified in additional clinical trials [17].

Concerning the relationship between age and knowledge about hormonal related breast cancer risk factors, higher levels of knowledge were identified among age groups 26 - 35 years and 36 - 45 years. These groups represent a section of the Saudi community with a broad culture, better education, and accumulative knowledge. During our search, we didn't come across studies investigated the role of age in the spread of awareness. Low deployment of breast cancer screening has been significantly linked to woman's age $(\mathrm{OR}=2.55 ; 95 \% \mathrm{CI}=$ 1.71 - 3.83), upper educational rank $(\mathrm{OR}=2.98 ; 95 \% \mathrm{CI}=2.05-4.34)$, greater family income $(\mathrm{OR}=1.96 ; 95 \% \mathrm{CI}=1.31-2.93)$, consuming hormonal contraception $(\mathrm{OR}=1.46 ; 95 \% \mathrm{CI}=0.99-2.13)$ and positive history of former breast $(\mathrm{OR}=12.16 ; 95 \% \mathrm{CI}=6.89-21.46[18]$.

On the other hand, higher levels of awareness were noticed among educated women (university level and secondary). Those less educated showed fewer awareness levels. Therefore, planned educational programs should target less educated women. A recent study from Saudi Arabia indicated educational interventions targeting raising breast cancer awareness and addressing barriers should be merged as the central part of the screening program in Saudi Arabia [18]. This calls for educational campaigns to boost breast cancer screening. Addressing the barriers for breast cancer screening is a public health authoritative [19].

In the present study, men showed low levels of awareness in all factors regarding breast risk. Though the incidence of men breast cancer is deficient, the men education may further improve the level of women awareness toward breast cancer and its associated risk factors with respect to the social construction of the Saudi community.

\section{Conclusion}

Saudi women are enthusiastically willing to raise their knowledge and awareness toward breast cancer prevention and control. Although women have greater knowledge about breast cancer risk factors compared to men, still some gaps need to be filled.

\section{Acknowledgements}

Authors would like to thank people of Alquriat and the students at Faculty of 
applied Medical Science at Alquriat.

\section{Conflicts of Interest}

The authors declare no conflicts of interest regarding the publication of this paper.

\section{References}

[1] Li, T., Mello-Thoms, C. and Brennan, P.C. (2016) Descriptive Epidemiology of Breast Cancer in China: Incidence, Mortality, Survival, and Prevalence. Breast Cancer Research and Treatment, 159, 395-406. https://doi.org/10.1007/s10549-016-3947-0

[2] Nagini, S. (2017) Breast Cancer: Current Molecular Therapeutic Targets and New Players. Anti-Cancer Agents in Medicinal Chemistry, 17, 152-163. https://doi.org/10.2174/1871520616666160502122724

[3] Ghoncheh, M., Pournamdar, Z. and Salehiniya, H. (2016) Incidence and Mortality and Epidemiology of Breast Cancer in the World. Asian Pacific Journal of Cancer Prevention, 17, 43-46. https://doi.org/10.7314/APJCP.2016.17.S3.43

[4] Ghoncheh, M., Momenimovahed, Z. and Salehiniya, H. (2016) Epidemiology, Incidence and Mortality of Breast Cancer in Asia. Asian Pacific Journal of Cancer Prevention, 17, 47-52. https://doi.org/10.7314/APJCP.2016.17.S3.47

[5] Eisemann, N., Waldmann, A. and Katalinic, A. (2013) Epidemiology of Breast Cancer-Current Figures and Trends. Geburtshilfe und Frauenheilkunde, 73, 130-135. https://doi.org/10.1055/s-0032-1328075

[6] Lozano, R., Naghavi, M., Foreman, K., Lim, S., Shibuya, K. and Aboyans, K. (2012) Global and Regional Mortality from 235 Causes of Death for 20 Age Groups in 1990 and 2010: A Systematic Analysis for the Global Burden of Disease Study 2010. Lancet, 380, 2095-2128. https://doi.org/10.1016/S0140-6736(12)61728-0

[7] Mokdad, A.H., Jaber, S., Aziz, M.I., AlBuhairan, F., AlGhaithi, A. and AlHamad, N.M. (2014) The State of Health in the Arab World, 1990010: An Analysis of the Burden of Diseases, Injuries, and Risk Factors. Lancet, 383, 309-320. https://doi.org/10.1016/S0140-6736(13)62189-3

[8] Alotaibi, R.M., Rezk, H.R., Juliana, C.I. and Guure, C. (2018) Breast Cancer Mortality in Saudi Arabia: Modelling Observed and Unobserved Factors. PLoS ONE, 13, e0206148. https://doi.org/10.1371/journal.pone.0206148

[9] Saggu, S., Rehman, H., Abbas, Z.K. and Ansari, A.A. (2015) Recent Incidence and Descriptive Epidemiological Survey of Breast Cancer in Saudi Arabia. Saudi Medical Journal, 36, 1176-1180. https://doi.org/10.15537/smj.2015.10.12268

[10] Samavat, H. and Kurzer, M.S. (2014) Estrogen Metabolism and Breast Cancer. Cancer Letters, 356, 231-243. https://doi.org/10.1016/j.canlet.2014.04.018

[11] Brewer, H.R., Jones, M.E., Schoemaker, M.J., Ashworth, A. and Swerdlow, A.J. (2017) Family History and Risk of Breast Cancer: An Analysis Accounting for Family Structure. Breast Cancer Research and Treatment, 165, 193-200. https://doi.org/10.1007/s10549-017-4325-2

[12] Vaidyanathan, K., Lakhotia, S., Ravishankar, H.M., Tabassum, U., Mukherjee, G. and Somasundaram, K. (2009) BRCA1 and BRCA2 Germline Mutation Analysis among Indian Women from South India: Identification of Four Novel Mutations and High-Frequency Occurrence of 185delAG Mutation. Journal of Biosciences, 34, 415-422. https://doi.org/10.1007/s12038-009-0048-9 
[13] Espié, M., Lalloum, M. and Coussy, F. (2013) Epidemiology and Risk Factors of Breast Cancer. Soins, 776, 22-24. https://doi.org/10.1016/j.soin.2013.04.003

[14] Vatten, L. (1998) Female Sex Hormones Increase the Risk of Breast Cancer. Tidsskrift for den Norske lægeforening, 118, 2969-2974.

[15] Jeong, S.H., An, Y.S., Choi, J.Y., et al. (2017) Risk Reduction of Breast Cancer by Childbirth, Breastfeeding, and Their Interaction in Korean Women: Heterogeneous Effects Across Menopausal Status, Hormone Receptor Status, and Pathological Subtypes. Journal of Preventive Medicine and Public Health, 50, 401-410. https://doi.org/10.3961/jpmph.17.152

[16] Sampson, J.N., Falk, R.T., Schairer, C., et al. (2016) Association of Estrogen Metabolism with Breast Cancer Risk in Different Cohorts of Postmenopausal Women. Cancer Research, 77, 918-925. https://doi.org/10.1158/0008-5472.CAN-16-1717

[17] Ruan, X., Seeger, H. and Mueck, A.O. (2012) Breast Cancer Risk during Hormone Therapy: Experimental versus Clinical Data. Minerva Endocrinologica, 37, 59-74.

[18] Abdel-Aziz, S.B., Amin, T.T., Al-Gadeeb, M.B., et al. (2018) Perceived Barriers to Breast Cancer Screening among Saudi Women at Primary Care Setting. Journal of Preventive Medicine and Hygiene, 59, E20-E29.

[19] El Bcheraoui, C., Basulaiman, M., Wilson, S., et al. (2015) Breast Cancer Screening in Saudi Arabia: Free But Almost No Takers. PLoS ONE, 10, e0119051.

https://doi.org/10.1371/journal.pone.0119051 